\title{
International consensus on ANA patterns (ICAP): the bumpy road towards a consensus on reporting ANA results
}

\author{
Jan Damoiseaux ${ }^{1}$ - Carlos A. von Mühlen ${ }^{2}$ Ignacio Garcia-De La Torre ${ }^{3}$. \\ Orlando Gabriel Carballo ${ }^{4,5}$ - Wilson de Melo Cruvinel $^{6}$ - Paulo Luiz Carvalho Francescantonio ${ }^{6}$. \\ Marvin J. Fritzler ${ }^{7}$ - Manfred Herold ${ }^{8}$ Tsuneyo Mimori, ${ }^{9,10}$ - Minoru Satoh ${ }^{11}$. \\ Luis E. C. Andrade ${ }^{12,13} \cdot$ Edward K. L. Chan ${ }^{14} \cdot$ Karsten Conrad $^{15}$
}

Received: 20 December 2015/Accepted: 25 December 2015/Published online: 30 January 2016

(C) The Author(s) 2016

\begin{abstract}
The International Consensus on ANA Patterns (ICAP) was initiated as a workshop aiming to thoroughly discuss and achieve consensus regarding the morphological patterns observed in the indirect immunofluorescence assay on HEp-2 cells. One of the topics discussed at the second ICAP workshop, and addressed in this paper, was the harmonization of reporting ANA test results. This discussion centered on the issue if cytoplasmic and mitotic patterns should be reported as positive or negative. This report outlines the issues that impact on two major different reporting methods. Although it was appreciated by all participants that cytoplasmic and mitotic patterns are clinically relevant, implications for existing diagnostic/classification criteria for ANA-associated diseases in particular hampered a final consensus on this topic.
\end{abstract}

Jan Damoiseaux

jan.damoiseaux@mumc.nl

1 Central Diagnostic Laboratory, Maastricht University Medical Center, Maastricht, P. Debyelaan 25, 6229 HX Maastricht, Netherlands

2 Brazilian Society of Autoimmunity, Porto Alegre, Brazil

3 Department of Immunology and Rheumatology, Hospital General de Occidente, University of Guadalajara, Guadalajara, Mexico

4 Laboratory of Immunology, Hospital Carlos G. Durand, Buenos Aires, Argentina

5 Department of Immunology, Instituto Universitario del Hospital Italiano, Buenos Aires, Argentina

6 Pontifícia Universidade Católica de Goiás, Goiânia, Brazil

7 Department of Medicine, Cumming School of Medicine, University of Calgary, Calgary, AB, Canada

8 Department of Internal Medicine VI, Medical University of Innsbruck, Innsbruck, Austria
Evidently, a more concerted action of all relevant stakeholders is required. Future ICAP workshops may help to facilitate this action.

Keywords Anti-nuclear antibodies - Indirect immunofluorescence $\cdot$ Nuclear patterns $\cdot$ Cytoplasmic patterns $\cdot$ Mitotic patterns $\cdot$ Harmonization

\section{Introduction}

Antinuclear antibodies (ANA) are important elements in the diagnosis of a variety of autoimmune diseases, especially ANA-associated rheumatic diseases (AARD) [1-3]. While ANA originally were detected by indirect

9 Department of the Control for Rheumatic Diseases, Graduate School of Medicine, Kyoto University, Kyoto, Japan

10 Department of Rheumatology and Clinical Immunology, Graduate School of Medicine, Kyoto University, Kyoto, Japan

11 Department of Clinical Nursing, University of Occupational and Environmental Health, Kitakyushu, Japan

12 Rheumatology Division, Escola Paulista de Medicina, Universidade Federal de São Paulo, São Paulo, Brazil

13 Fleury Medicine and Health Laboratories, Immunology Division, São Paulo, Brazil

14 Department of Oral Biology, University of Florida, Gainesville, FL, USA

15 Institute of Immunology, Technical University of Dresden, Dresden, Germany 
immunofluorescence (IIF) [4], several alternative methods have entered the market [5]. Although this has raised many discussions on the definition and positioning of ANA testing [6-8], ANA detection by IIF has the advantage of obtaining information on the IIF staining pattern, which is considered of added clinical value. The introduction of HEp-2 cells as the substrate for ANA IIF has increased the awareness that, besides nuclear patterns, cytoplasmic and mitotic cell patterns can also be recognized. As such, the term anti-cellular antibodies has been suggested to encompass the wider spectrum of these autoantibodies $[8$, 9]. However, because the use of the acronym ANA is firmly established and universally used, replacement by an alternative terminology will not be easy. Changes in nomenclature would have many implications, for instance for existing guidelines, disease criteria, external quality control programs, education, and reimbursement policies.

The International Consensus on ANA Patterns (ICAP) initiative started in 2014 as a workshop parallel to the 12th International Workshop on Autoimmunity and Autoantibodies (IWAA) in Sao Paulo, Brazil [10]. This first ICAP workshop was devoted to establishing a consensus on the nomenclature of the distinct ANA patterns recognized by IIF on HEp- 2 cells. This resulted in a classification tree that distinguishes three major IIF staining categories: nuclear, cytoplasmic and mitotic patterns [11]. The second ICAP workshop was recently hosted in conjunction with the 12th Dresden Symposium on Autoantibodies in Dresden, Germany. Since it was recognized that standardization and harmonization in autoimmune diagnostics is of utmost importance, part of the discussion was focused on the reporting of ANA results. The discussion was prepared in advance by Carlos von Mühlen (Brazil), Ignacio Garcia De La Torre (Mexico), and Jan Damoiseaux (The Netherlands). The input included a number of (inter)national recommendations on this topic $[1,6,8,9,12-18]$ and two proposals.

Here we register the discussion with a focus on two main points regarding the articulation of the ANA report: (1) the position of cytoplasmic and mitotic patterns, i.e., are they to be reported as ANA negative or ANA positive; and (2) the advice to clinicians on the possible significance of the patterns observed, i.e., possibly involved autoantibodies and associated diseases.

\section{(Inter)National recommendations on ANA reporting}

A non-exhaustive review of the currently available recommendations on reporting ANA results is provided in Table 1. It was generally agreed that the report should contain information on the type of immunoassay that has been used. On the other hand, if an ANA pattern is reported, this implies that ANA were determined by IIF because alternative methods do not allow pattern recognition. Surprisingly, almost none of the recommendations made a statement on reporting ANA simply as negative or positive. In the case of ANA IIF, again this may be surpassed by providing a titer and/or pattern. However, in relation to the discussion whether a cytoplasmic or mitotic apparatus staining pattern is to be considered ANA positive, a straightforward interpretation in terms of "ANA negative" or "ANA positive" was thought to be helpful. In Argentina, Belgium and Brazil, it is recommended that results for distinct cellular compartments are reported, but this does not unequivocally imply that a cytoplasmic/mitotic apparatus reactivity is to be considered ANA positive $[9,16,18]$. In the second Brazilian consensus on ANA in HEp-2 cells, however, it was decided that cytoplasmic patterns are to be considered ANA positive, but a subtitle is to be added to the report, stating that "ANA is actually a test that detects autoantibodies to cellular antigens-thus encompassing the whole cellular anatomy and all cellular structures" [9]. Also, the Italian recommendations of the Forum Interdisciplinare per la Ricerca nelle Mallattie Autoimmuni (FIRMA) explicitly state that a cytoplasmic pattern is to be considered ANA positive (http://www. gruppofirma.com). Neither the ACR nor the EASI/IUIS recommendations state a clear position towards cytoplasmic/mitotic apparatus patterns being considered ANA negative or positive $[1,6,8]$. The EASI/IUIS recommendation only states "besides nuclear patterns also cytoplasmic and mitotic apparatus patterns should be reported and specified when possible" [8]. Finally, the European Consensus Finding Study Group on Laboratory Investigation in Rheumatology (ECGSG), being part of the European League Against Rheumatism (EULAR), considers a cytoplasmic pattern as ANA negative (personal communication Johan Rönnelid, Sweden).

Recommendations about titer and pattern are obviously restricted to the IIF method for ANA detection. Titration is considered clinically relevant since a higher titer is associated with a higher positive likelihood ratio to confirm a diagnosis of an AARD [19, 20]. Furthermore, a higher titer also increases the chance of identifying the antigen that is recognized in the ANA IIF test by antigen-specific immunoassays [21, 22]. These findings, however, are challenged by the introduction of newer technologies. The added value of extremely high titers is considered to be limited as can be concluded from the fact that in several recommendations an end-point titer is defined beyond which no further dilutions are needed. Nevertheless, both the ACR and EASI/IUIS recommendations advised to perform an end-point titration [1,8]. Alternatively, the Dutch and Italian recommendations allow reporting fluorescence intensity instead of the titer [13; http://www. gruppofirma.com]. This option may be valuable as some of 


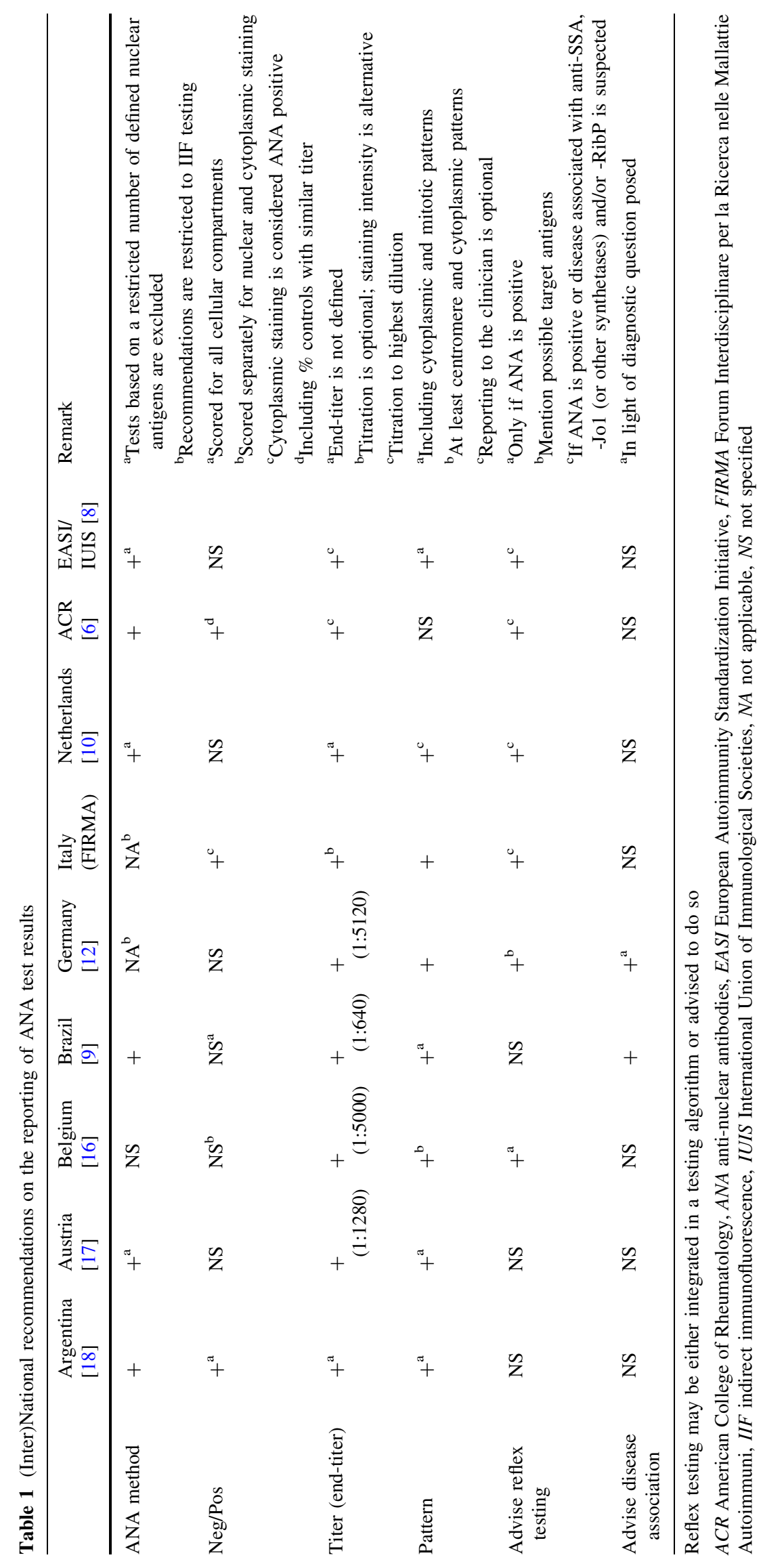


the newer automated digital ANA reading systems score the fluorescence intensity and even project end-point titers on a single well dilution, and, importantly, these intensities seem to correlate quite well with the end-point titers $[5,23$, 24]. The relevance of reporting ANA patterns is underscored by all recommendations, except for the ACR recommendations. In the Netherlands, though, reporting can be decided locally upon consultation with the clinicians involved [10].

Finally, the recommendations differentially touch on the issue of advice to be added for interpretation of the results obtained. Although many laboratories use general remarks with respect to possible disease associations, most recommendations do not address this point. Only the Brazilian consensus strongly recommends the inclusion of such remarks in the ANA report [9], and in the German consensus such advice is only provided in the light of the diagnostic question posed [12]. There is, however, more consensus about the recommendations in the context of reflex testing. In Germany, it is recommended to mention possible target antigens, based on the ANA pattern and the clinical information provided [12]. Depending on the reimbursement policies as determined by individual jurisdictions, the reflex testing can be preempted in a testing algorithm. In that case, advice about reflex testing is redundant.

\section{Two proposals for reporting of ANA test results}

During the second ICAP workshop, two alternative recommendations for reporting of ANA test results were discussed. These alternatives only differed with respect to cytoplasmic and mitotic patterns being considered ANA positive or negative (Fig. 1). In these proposals the report should consist of 3 items: type of assay used, test result, and, if appropriate, advice on reflex testing. These items were chosen based on being the common denominator in the examined (inter)national recommendations (Table 1).

\section{Examples illustrating the recommendations for reporting ANA test results}

Proposal 1: cytoplasmic \& mitotic patterns considered ANA positive

\begin{tabular}{|c|c|}
\hline $\begin{array}{l}\text { Assay: } \\
\text { Result: } \\
\text { Advice: }\end{array}$ & $\begin{array}{l}\text { ANA on HEp-2 cells } \\
\text { Negative } \\
\text { - }\end{array}$ \\
\hline $\begin{array}{l}\text { Assay: } \\
\text { Result: } \\
\text { Advice: }\end{array}$ & $\begin{array}{l}\text { ANA on HEp- } 2 \text { cells } \\
\text { Positive, cytoplasmic speckled, 1:80 } \\
\text { In case of suspicion of myositis, consider further testing } \\
\text { for anti-synthetases, e.g. Jo-1 }\end{array}$ \\
\hline $\begin{array}{l}\text { Assay: } \\
\text { Result: }\end{array}$ & $\begin{array}{l}\text { ANA on HEp-2 cells } \\
\text { Positive, nuclear speckled, 1:160 and cytoplasmic } \\
\text { reticular/AMA, 1:1280 }\end{array}$ \\
\hline Advice: & $\begin{array}{l}\text { In case of suspicion of autoimmune liver disease, } \\
\text { consider confirmation of anti-mitochondrial antibodies }\end{array}$ \\
\hline $\begin{array}{l}\text { Assay: } \\
\text { Result: }\end{array}$ & $\begin{array}{l}\text { ANA on HEp- } 2 \text { cells } \\
\text { Positive, centromere, 1:1280 and nuclear homogeneous, } \\
\text { 1:80 }\end{array}$ \\
\hline Advice: & $\begin{array}{l}\text { In case of suspicion of systemic sclerosis, consider } \\
\text { confirmation of anti-CENP-B antibodies }\end{array}$ \\
\hline
\end{tabular}

Fig. 1 Examples illustrating the recommendations for reporting of ANA test results. The report consists of three categories: the type of assay used, the test results (positive/negative, pattern, and antibody level), and the advice for the clinician. In proposal 1 (left), cytoplasmic (and mitotic) patterns are considered ANA positive, while in proposal 2 (right), cytoplasmic (and mitotic) patterns are considered ANA negative. The examples shown illustrate alternate possibilities according to the rules in each proposal for reporting ANA test results. If the test result is negative (a), this is reported as such in both proposals. If only a cytoplasmic staining is observed (b), the result is reported as ANA positive in proposal 1 and as ANA negative in proposal 2 . The items positive and negative are highlighted to emphasize the difference in the proposals. In both
Proposal 2: cytoplasmic \& mitotic patterns considered ANA negative

\begin{tabular}{|c|c|}
\hline Assay: & ANA on HEp-2 cells \\
\hline Result: & Negative \\
\hline Advice: & - \\
\hline Assay: & ANA on HEp-2 cells \\
\hline Result: & Negative, cytoplasmic speckled, 1:80 \\
\hline Advice: & $\begin{array}{l}\text { In case of suspicion of myositis, consider further testing } \\
\text { for anti-synthetases, e.g. Jo-1 }\end{array}$ \\
\hline Assay: & ANA on HEp-2 cells \\
\hline Result: & $\begin{array}{l}\text { Positive, nuclear speckled, 1:160 and cytoplasmic } \\
\text { reticular/AMA, 1:1280 }\end{array}$ \\
\hline Advice: & $\begin{array}{l}\text { In case of suspicion of autoimmune liver disease, } \\
\text { consider confirmation of anti-mitochondrial antibodies }\end{array}$ \\
\hline Assay: & ANA on HEp-2 cells \\
\hline Result: & $\begin{array}{l}\text { Positive, centromere, } 1: 1280 \text { and nuclear homogeneous, } \\
1: 80\end{array}$ \\
\hline Advice: & $\begin{array}{l}\text { In case of suspicion of systemic sclerosis, consider } \\
\text { confirmation of anti-CENP-B antibodies }\end{array}$ \\
\hline
\end{tabular}

proposals this result is followed by the statement of the cytoplasmic pattern and antibody level (titer). If a combination of nuclear and cytoplasmic patterns is observed (c), the result is reported as positive in both proposals because of the nuclear staining. According to the rule that patterns are reported in the sequence nuclear-cytoplasmic-mitotic, irrespective of the antibody level, the nuclear pattern is mentioned first even when the antibody level of the cytoplasmic pattern is higher. If a combination of different nuclear patterns is observed (d), the nuclear pattern with the highest antibody level is to be reported first. The advice to the clinician may be similar for the respective situations in both proposals. The lay-out of the report can be adjusted to be compatible with the local hospital information system 
The item "type of assay" should specify the method used, i.e., IIF on HEp-2 cells or alternative HEp-2 substrates, addressable-laser bead immuno-assay (ALBIA), enzymelinked immunosorbent assay (ELISA), etc. Providing also the name of the assay kit manufacturer is considered important because it is known that some autoantibodies and their respective patterns show-up preferentially in some HEp-2 slide brands, such as anti-SS-A/Ro60 on HEp-2000 substrates and the anti-rods and rings pattern [11, 24]. It was felt, however, that such information is not relevant for the majority of patterns and autoantibodies.

The second item of the report should contain information on the ANA test being positive or negative, the IIF pattern, and the autoantibody titer. The results should be reported in the sequence: positive/negative-pattern-titer. Evidently, reporting an ANA pattern as a test result only applies to ANA IIF results on HEp-2 cells. The nomenclature for ANA patterns should be according the consensus reached in the first ICAP workshop [11]. The autoantibody level can be expressed as titer, fluorescence intensity as being generated by automated digital ANA reading devices, or arbitrary units obtained by alternative ANA assays. The two proposals differ in the assignment of positive/negative because, in contrast to the first proposal, in the second proposal, cytoplasmic and mitotic ANA patterns are considered ANA negative. In case of mixed patterns, all nuclear patterns are reported first and next cytoplasmic, and then mitotic patterns. Each pattern is directly followed with the respective titer. Within each category, i.e., nuclear, cytoplasmic, and mitotic, the pattern with the highest titer is mentioned first. In the second proposal a sample with an exclusively cytoplasmic pattern is reported as negative (with statement of the cytoplasmic pattern and titer), whereas a sample with mixed nuclear and cytoplasmic pattern is reported as ANA positive. Examples for reporting distinct test results are provided in Fig. 1.

The third item of the report, addressing advice for reflex testing in the clinical context, is similar in both proposals. It was strongly advised against providing clinical associations. It was concluded in a separate ICAP discussion, prepared by Minoru Satoh (Japan) and Jan Damoiseaux (The Netherlands), that the clinical associations with ANA patterns are poorly defined. At best, the patterns hint at the antigens recognized and merely the cognate autoantibodies are associated with certain diseases or manifestations of diseases. There is no consensus yet regarding the use of general remarks, like "ANA must be interpreted according to the clinical picture" or " $10 \%$ of normal persons may have a positive result" to enable better interpretation of the test results. Further information on interpretation of the test results obtained, however, is considered to be important. The clearly desired goal is to inevitably develop consensus on the content of this information.

\section{Pros and cons for considering cytoplasmic and mitotic patterns as ANA positive}

First of all, it is important to recognize that the ICAP discussion on how to report cytoplasmic and mitotic patterns was not just a semantic discussion. As already mentioned, it is widely accepted that the IIF test on HEp-2 cells enables the detection of both nuclear and non-nuclear reactivity. Changing the name of the test to something other than ANA might, for instance, impact on reimbursement policies in several jurisdictions and, therefore, was considered not feasible at this point of time. Interestingly, both the ACR and EASI/IUIS recommendations allow the use of alternative techniques for ANA detection $[6,8]$. When applying these alternative immunoassays, however, there appears to be no discussion on the fact that these tests also may reveal a positive result based on the reactivity towards (clinically relevant) non-nuclear autoantigens, for instance Jo-1 or ribosomal P protein. To be consistent with these alternative techniques, this may be used as an argument to also consider cytoplasmic and mitotic patterns as ANA positive. The most important argument for reporting cytoplasmic patterns as ANA positive is the overall acceptance by the ICAP participants as well as the literature that cytoplasmic patterns are clinically relevant $[5,8,11,26]$. If such a pattern is reported as negative, the additional information in the report on pattern and titer may go unnoticed because clinicians tend to pay less attention to negative results. In Brazil, cytoplasmic patterns have been reported as ANA positive for more than a decade [9]. This has not raised any complaints from either the laboratory or the clinical perspective. An important adjustment that has been implemented in the report of ANA results is the use of a subtitle of the ANA test indicating that the results include more than just the nuclear ANA patterns.

On the other hand, there were also strong arguments against reporting cytoplasmic and/or mitotic patterns as ANA positive. First, from the scientific point of view ANA are defined as autoantibodies directed against nuclear antigens. Second, ANA are included in diagnostic and/or classification criteria for systemic lupus erythematosus (SLE), Sjögren's syndrome, mixed connective tissue disease (MCTD), systemic sclerosis (SSc), and autoimmune hepatitis (AIH) [27-35]. In case of SLE, both in the ACR as well as in the more recent SLICC criteria, a positive ANA test is an important hallmark of the disease [27, 28]. While in the 1982 ACR criteria it is explicitly stated that ANA are to be determined by IIF, no details are provided either in the revised ACR or the SLICC criteria about the interpretation of cytoplasmic and mitotic patterns. Similarly, in the criteria for the Sjögren's syndrome and MCTD, critical results are defined on the ANA titer, indicating that 
IIF is the method of choice $[29,30]$. Although it is anticipated that the ANA mentioned in the criteria only concerns true nuclear reactivity, none of the AARD criteria, except for the SSc criteria that entail the centromere pattern, has defined which IIF patterns are to be considered positive. Obviously, by defining cytoplasmic and mitotic patterns as ANA positive, test characteristics will change and influence the validity of the criteria. It should be noted, though, that the AARD criteria mentioned are all classification criteria, which are distinct from diagnostic criteria [36]. The criteria for $\mathrm{AIH}$, however, are diagnostic criteria [33-35]. These criteria are linked to a consensus on the detection of autoantibodies in the autoimmune liver diseases [37]. Although it is stated that for AIH an ANA test is to be performed by IIF, it is speculated that in the future more refined techniques using other immuno-assay formats may enable identification of reactants and assessment of their use for diagnosis of AIH [37]. It is evident from these criteria, however, that only nuclear patterns are to be interpreted as ANA positive. This is best illustrated by the extended AIH criteria $[33,35]$ in which a diagnosis of AIH is based on a scoring system. Parameters positively associated with AIH reveal positive scores, while parameters that direct towards other diagnoses reveal negative scores. As such, a positive ANA may give, depending on the titer, up to 3 points. On the other hand, the presence of antimitochondrial antibodies gives a negative score of 4 points. Obviously, this scoring system goes wrong if the cytoplasmic reactivity of anti-mitochondrial antibodies is reported as ANA positive. A third argument against reporting cytoplasmic patterns as ANA positive concerns external quality control (EQC) programs. Indeed, some EQC providers, like UK-NEQAS, require that a cytoplasmic pattern is reported as ANA negative in order to have a full score in the EQC assessment. Obviously, if worldwide consensus on ANA reporting can be achieved, this will inevitably result in adjustment of the EQC scoring.

When considering these arguments, however, one should keep in mind that a long history of technical and scientific evolution regularly reshapes and optimizes regulations and classifications. Therefore, concerns with reimbursement, classification criteria and EQC programs might be considered as relative arguments, since recommendations from an international board of specialists, such as the ICAP, should be able to foster sound and relevant update regarding the interests of all involved stakeholders.

Altogether, the discussion on cytoplasmic and mitotic patterns has not yet reached consensus. Members of the ICAP acknowledged that further discussion is needed for reflection and maturation of this issue. It is anticipated that summarizing the current status of the discussion will be of help to come to a widely accepted consensus.

\section{Conclusions}

The clinical value of ANA testing for AARD and autoimmune liver diseases is beyond doubt, but harmonization of reporting ANA test results still needs a few hurdles to take. The current report on the ICAP discussion on reporting of ANA test results, and in particular the issue of cytoplasmic and mitotic patterns being ANA positive or negative, illustrates the intertwining of diagnostic/classification criteria for distinct diseases associated with ANA, methodologic consensus statements, semantic issues, as well as political issues like reimbursement policies and hedging for legal claims. What is needed is a paradigm shift to get out of a vicious circle. The question is, though, where to start? Obviously, the name of the test appears not to be the biggest hurdle. For the time being, there is agreement that the community can live with a misnomer, eventually extended by a subtitle that gives credit to the fact that also non-nuclear autoantibodies can be detected. For alignment of methodological consensus statements, like ICAP and diagnostic/classification criteria, there is a need for close collaboration with the clinical parties that are responsible for the respective criteria. This will create mutual understanding of, and eventually a solution to, the current dichotomy with respect to the interpretation of cytoplasmic and mitotic patterns. If a consensus between all stakeholders is achieved and consistently applied in the relevant documents, there will be a strong motive to also solve the jurisdictional issues and eventually the nomenclature. Full integration of this paradigm shift in the (medical) community will require a transition period in order to facilitate the requested adaptations.

With respect to the interpretation of the test results obtained and the possible advice provided to the clinician, there was consensus that information on the antigens possibly recognized as based on the ANA pattern was more relevant than information on the possible disease association. In the end, a laboratory test is only useful if requested in the appropriate clinical context. It was suggested that for standardization purposes it would be helpful to prepare examples of these advices for each distinct ANA pattern, preferentially in relation to the clinical information provided alongside the ANA request. These advices should be made available on the ICAP website (http://www.anapat terns.org). If pattern and antigen-specificity are concordant, this will also increase the clinical value of the combined laboratory result.

Altogether, the activity of the ICAP initiative has been very successful in bringing up and disseminating the importance of the correct identification and denomination of the various IIF patterns observable in the ANA-HEp-2 test. The discussion on reporting of ANA results upheld 
during the second ICAP has pinpointed additional issues that need to be addressed in forthcoming ICAP workshops.

Acknowledgments The authors thank the German Association of Clinical Chemistry and Laboratory Medicine (DGKL e. V.) for sponsoring the 2nd ICAP workshop in Dresden. Furthermore, we thank all participants of the 2nd ICAP workshop for their valuable contribution to the discussion. In particular, we thank Nicola Bizzaro (Italy), Xavier Bossuyt (Belgium), Pier-Luigi Meroni (Italy), and Johan Rönnelid for additional input on this topic.

\section{Compliance with ethical standards}

Conflict of interest MF has honoraria and consultation (INOVA Diagnostics Inc and Euroimmun $\mathrm{GmbH}$ ). Other authors have none.

Ethical approval This article does not contain any studies with human participants or animals performed by any of the authors.

Informed consent This article does not contain any studies with human participants performed by any of the authors and therefore informed consent is not applicable.

\section{References}

1. Solomon DH, Kavanaugh AJ, Schur PH (2002) Evidence-based guidelines for the use of immunologic tests: antinuclear antibody testing. Arthritis Rheum 47:434-444

2. Mahler M, Fritzler MJ (2012) The clinical significance of the dense fine speckled immunofluorescence pattern on HEp-2 cells for the diagnosis of systemic autoimmune diseases. Clin Dev Immunol 2012:494356

3. Satoh M, Tanaka S, Ceribelli A, Calise SJ, Chan EK (2015) A Comprehensive overview on myositis-specific antibodies: new and old biomarkers in idiopathic inflammatory myopathy. Clin Rev Allergy Immunol. doi:10.1007/s12016-015-8510-y

4. Coons AH, Kaplan MH (1950) Localization of antigen in tissue cells; improvements in a method for the detection of antigen by means of fluorescent antibody. J Exp Med 91:1-13

5. Mahler M, Meroni PL, Bossuyt X, Fritzler MJ (2014) Current concepts and future directions for the assessment of autoantibodies to cellular antigens referred to as anti-nuclear antibodies. J Immunol Res 2014:315179

6. Meroni PL, Schur PH (2010) ANA screening: an old test with new recommendations. Ann Rheum Dis 69:1420-1422

7. Fritzler MJ (2011) The antinuclear antibody (ANA) test: last or lasting gasp? Arthritis Rheum 16:19-22

8. Agmon-Levin N, Damoiseaux J, Kallenberg C, Sack U, Witte T, Herold $M$ et al (2014) International recommendations for the assessment of autoantibodies to cellular antigens referred to as anti-nuclear antibodies. Ann Rheum Dis 73:17-23

9. Dellavance A, Junior AG, Cintra AFU, Ximenes AC, Nuccitelli B, Taliberti BH et al (2003) Brazilian consensus on antinuclear antibodies in HEp-2 cells. Definitions for standardization of autoantibody testing against the nucleus (ANA HEP-2), nucleolus, cytoplasm and mitotic apparatus, as well as its clinical associations. Rev Bras Reumatol 43:129-140

10. Damoiseaux J, Andrade LE, Fritzler MJ, Shoenfeld Y (2015) Autoantibodies 2015: from diagnostic biomarkers toward prediction, prognosis and prevention. Autoimmun Rev 14:555-563

11. Chan EK, Damoiseaux J, Carballo OG, Conrad K, de Melo Cruvinel W, Francescantonio PL et al (2015) Report of the first international consensus on standardized nomenclature of antinuclear antibody HEp-2 cell patterns 2014-2015. Front Immunol 6:412

12. Sack U, Conrad K, Csernok E, Frank I, Hiepe F, Krieger T et al (2009) Autoantibody detection using indirect immunofluorescence on HEp-2 cells. Ann NY Acad Sci 1173:166-173

13. Damoiseaux J, Bakker-Jonges L, Cohen Tervaert JW, Derksen R, Hooijkaas H, Kallenberg C et al (2010) Laboratory diagnosis of ANA, anti-ds-DNA- and anti- ENA-antibodies: recommendation following the outcomes of a questionnaire. Ned Tijdschr Klin Chem Labgeneesk 35:234-239

14. Francescantonio PL, de Melo Cruvinel W, Dellavance A, Andrade LE, Taliberti BH et al (2014) IV Brazilian guidelines for autoantibodies on HEp-2 cells. Rev Bras Reumatol 54:44-50

15. Yazdany J, Schmajuk G, Robbins M, Daikh D, Beall A, Yelin E et al (2013) Choosing wisely: the American College of Rheumatology's top 5 list of things physicians and patients should question. Arthritis Care Res Hoboken 65:329-339

16. Van Blerk M, Bossuyt X, Humbel R, Mewis A, Servais G, Tomasi JP et al (2014) Belgian recommendations on ANA, antidsDNA and anti-ENA antibody testing. Acta Clin Belg 69:83-86

17. Herold M, Klotz W, Demel U, Endler G, Forster E, Griesmacher A et al (2015) International consensus on ANA determinationwhat changes in the German-speaking area? LaboratoriumsMedizin 39:145-152

18. Carballo OG, Ingenito FB, Ginaca AA, Carabajal P, Costa MA, Balbaryski J (2012) First Argentine consensus for standardization of antinuclear antibodies by indirect immunofluorescence-HEp- 2 . Acta Bioquím Clín Latinoam 46:3-13

19. Mariz HA, Sato EI, Barbosa SH, Rodrigues SH, Dellavance A, Andrade LE (2011) ANA-HEp-2 pattern is a critical parameter for discriminating ANA-positive healthy individuals and patients with autoimmune rheumatic diseases. Arthritis Rheum 63:191-200

20. Op De Beeck K, Vermeersch P, Verschueren P, Westhovens R, Mariën G, Blockmans D et al (2011) Detection of antinuclear antibodies by indirect immunofluorescence and by solid phase assay. Autoimmun Rev 10:801-808

21. Bossuyt X, Hendrickx A, Frans J (2005) Antinuclear antibody titer and antibodies to extractable nuclear antigens. Arthritis Rheum 53:987-988

22. Damoiseaux JG, Tervaert JW (2006) From ANA to ENA: how to proceed? Autoimmun Rev 5:10-17

23. Bonroy C, Verfaillie C, Smith V, Persijn L, De Witte E, De Keyser F et al (2013) Automated indirect immunofluorescence antinuclear antibody analysis is a standardized alternative for visual microscope interpretation. Clin Chem Lab Med 51:1771-1779

24. Schouwers S, Bonnet M, Verschueren P, Westhovens R, Blockmans D, Mariën G et al (2014) Value-added reporting of antinuclear antibody testing by automated indirect immunofluorescence analysis. Clin Chem Lab Med 52:547-551

25. Fritzler MJ, Hanson C, Miller J, Eystathioy T (2002) Specificity of autoantibodies to SS-A/Ro on a transfected and overexpressed human $60 \mathrm{kDa}$ Ro autoantigen substrate. J Clin Lab Anal 16:103-108

26. Wiik AS, Hoier-Madsen M, Forslid J, Charles P, Meyrowitsch J (2010) Antinuclear antibodies: a contemporary nomenclature using HEp-2 cells. J Autoimmun 35:276-290

27. Tan EM, Cohen AS, Fries JF, Masi AT, McShane DJ, Rothfield NF et al (1982) The 1982 revised criteria for the classification of systemic lupus erythematosus. Arthritis Rheum 25:1271-1277

28. Petri M, Orbai AM, Alarcón GS, Gordon C, Merrill JT, Fortin PR et al (2012) Derivation and validation of the Systemic Lupus International Collaborating Clinics classification criteria for systemic lupus erythematosus. Arthritis Rheum 64:2677-2686

29. Shiboski SC, Shiboski CH, Criswell L, Baer A, Challacombe S, Lanfranchi $\mathrm{H}$ et al (2012) American College of Rheumatology 
classification criteria for Sjögren's syndrome: a data-driven, expert consensus approach in the Sjögren's International Collaborative Clinical Alliance cohort. Arthritis Care Res 64:475-487

30. Amigues JM, Cantagrel A, Abbal M, Mazieres B (1996) Comparative study of 4 diagnosis criteria sets for mixed connective tissue disease in patients with anti-RNP antibodies. Autoimmunity Group of the Hospitals of Toulouse. J Rheumatol 23:2055-2062

31. van den Hoogen F, Khanna D, Fransen J, Johnson SR, Baron M, Tyndall A et al (2013) 2013 classification criteria for systemic sclerosis: an American College of Rheumatology/European League against Rheumatism collaborative initiative. Arthritis Rheum 65:2737-2747

32. Meroni PL, Biggioggero M, Pierangeli SS, Sheldon J, Zegers I, Borghi MO (2014) Standardization of autoantibody testing: a paradigm for serology in rheumatic diseases. Nat Rev Rheumatol $10: 35-43$
33. Alvarez F, Berg PA, Bianchi FB, Bianchi L, Burroughs AK, Cancado EL et al (1999) International Autoimmune Hepatitis Group Report: review of criteria for diagnosis of autoimmune hepatitis. J Hepatol 31:929-938

34. Hennes EM, Zeniya M, Czaja AJ, Pares A, Dalekos GN, Krawitt EL et al (2008) Simplified criteria for the diagnosis of autoimmune hepatitis. Hepatology 48:169-176

35. Liberal R, Grant CR, Longhi MS, Mieli-Vergani G, Vergani D (2014) Diagnostic criteria of autoimmune hepatitis. Autoimmun Rev 13:435-440

36. Aggarwal R, Ringold S, Khanna D, Neogi T, Johnson SR, Miller A et al (2015) Distinctions Between Diagnostic and Classification Criteria? Arthritis Care Res Hoboken 67:891-897

37. Vergani D, Alvarez F, Bianchi FB, Cancado EL, Mackay IR, Manns MP et al (2004) Liver autoimmune serology: a consensus statement from the committee for autoimmune serology of the International Autoimmune Hepatitis Group. J Hepatol $41: 677-683$ 